\title{
Sustainable Consumption Behavior at Home and in the Workplace: Avenues for Innovative Solutions
}

\author{
Jūratė Banytė ${ }^{1, *}$, Laura Šalčiuvienè ${ }^{1}$, Aistè Dovalienė ${ }^{1}$, Žaneta Piligrimienè ${ }^{1}$ (I) and \\ Włodzimierz Sroka ${ }^{2,3}$ \\ 1 School of Economics and Business, Kaunas University of Technology, Gedimino str. 50, \\ 44239 Kaunas, Lithuania; laura.salciuviene@ktu.lt (L.Š.); aiste.dovaliene@ktu.lt (A.D.); \\ zaneta.piligrimiene@ktu.lt (Ž.P.) \\ 2 Management Department, WSB University, Zygmunta Cieplaka str. 1c, 41-300 Dąbrowa Górnicza, Poland; \\ wsroka@wsb.edu.pl \\ 3 TRADE Research Entity, North West University, 11 Hoffman str., Potchefstroom 2351, South Africa \\ * Correspondence: jurate.banyte@ktu.lt
}

Received: 22 July 2020; Accepted: 10 August 2020; Published: 13 August 2020

check for updates

\begin{abstract}
Companies which offer innovative solutions to aid the achievement of sustainable consumption behavior of individuals in home environment gain a competitive advantage. The study aims to uncover the relationship between the engagement in sustainable consumption and sustainable consumption behavior of individuals at home and in the workplace environments enabling companies to provide innovative solutions to advance sustainability management. This research holds that sustainable consumption behavior is a process and the focus of this study is use behavior. An online survey was employed to collect data from 407 respondents in the United Kingdom. Consumers working in both private and public sectors were surveyed. Data analysis suggests that one dimension of engagement in sustainable consumption, namely, Enthusiasm and Attention, mostly influences sustainable consumption behavior at home and in the workplace. Further, females feature higher sustainable consumption behavior at home and in the workplace most of the time in comparison to males. Also, there are age differences apropos sustainable consumption behavior at home and in the workplace. Social Learning Theory and Collaborative Consumption Theory are used to raise hypotheses and explain findings. The findings lead to practical implications for companies regarding engagement and sustainable consumption behavior in both environments in terms of incentives, green product and service innovation that may be offered to individuals to enhance sustainability.
\end{abstract}

Keywords: engagement in sustainable consumption; sustainable consumption behavior; home and workplace environments; innovative solutions

\section{Introduction}

In today's competitive environment and with ever-increasing environmental pollution, companies call for sustainable production and consumption through sustainable employee behavior in the workplace [1] and home environments [2]. Escalating environmental pollution requires urgent action and companies can approach this phenomenon in conventional or innovative ways. By providing novel decisions to individuals at work, which are based on pro-environmental choices, companies could aid the improvement of sustainable consumption behavior both at work and in personal life. The author of one of the most recent works on this topic, Piwowar-Sulej [3], notes the importance of the pro-environmental organizational culture and highlights the relevance of the identification of factors that determine pro-environmental employee behavior. However, in order to achieve a significant improvement in the sustainable consumption behavior of individuals, understanding of their behavior 
in different environments is important in both private life and work environments. The argument of this claim is supported by the findings of Muster and Schrader [4], Yusoff et al. [5], Gadeikienè et al. [6], Piligrimiene et al. [7]. Muster and Schrader [4] theoretically justify the idea of a green work-life balance, while Gadeikiene et al. [6] conceptualize sustainable consumption behavior spill-over from the workplace to private life. In Piligrimiene et al.'s [7] work, work-life balance, or conflict, is analyzed as a factor of sustainable consumption. Thus, work-life balance can be identified as a driver of sustainable consumption behavior integrating both work and personal life. Meanwhile, a review and synthesis of the current research findings indicates that a few recent studies on sustainable consumption behavior have focused on both work and home environments. This limits a better understanding of sustainable consumption behavior and leads to a lack of practical and theoretical solutions enabling such behavior, while at the same time pointing to the direction of further research into sustainable consumption behavior at home and in the workplace.

It has been acknowledged that attitudes alone are not a great predictor of use behavior of individuals due to the attitude-behavior gap identified by earlier studies (e.g., [8,9]). However, even with low motivation to consume sustainable products, such individuals might change their behavior due to a perceived greater good [8] or due to their perceptions of responsibility towards the environment [10]. It is, therefore, likely that the identification of factors contributing to the behavior of sustainable consumption will, lead to more specific and long-lasting results. This will bring environmental benefits, such as landfilling of waste, and using collaborative consumption in the community will aid in addressing social challenges. To date, research that has been carried out in the management and other fields (e.g., [11-14]) reveals its focus on pro-environmental behavior and most of the time it emphasizes the environmental, or ecological, dimension of sustainable consumption. Blok et al. [12] interprets pro-environmental behavior as being synonymous with sustainable consumption behavior, linking their definitions to the reduction of the negative influence of human behavior on the environment. Kadic-Maglajlic et al. [15] and Hosta and Zabkar [16]'s studies, which represent the recent developments of the marketing field, are based on the notion that pro-environmental consumption and pro-social consumption behavior are two different forms of sustainable consumption behavior.

The authors of this manuscript support the view that in order to achieve a holistic understanding of sustainable consumption behavior, both pro-environmental and pro-social behavior indicators must be analyzed. Also, in this context, the findings of Gupta and Agrawal [17] and Geiger et al. [18] are used to support the constructs of sustainable consumption behavior at home and in the workplace, which include not only environmentally friendly or conscious constructs, but also collaborative consumption indicators. Although it has been widely acknowledged in the literature that sustainable consumption behavior is a process comprising three phases [18,19], in order to achieve a deeper understanding of the phenomenon, only one phase, that is use behavior, was chosen to be tested empirically in this study.

Earlier research on factors contributing to sustainable consumption behavior also confirms the dominance of factors related to the environmental aspects. For example, Alcock et al. [14] analyze the link between nature exposure, nature appreciation and pro-environmental behavior and Whitburn et al. [13] investigate the effects of individuals' connection to nature on pro-environmental behavior. Also, it should be noted that individual authors who have studied sustainable consumption behavior in personal life, such as Joshi and Rahman [20], distinguish between personal, behavioral and socio-cultural factors, while Hosta and Zabkar [16] reveal a willingness to behave in a environmentally/socially responsible way and the role of related variables. As regards the behavior of sustainable consumption in the workplace, the works of Blok et al. [12], Wesselink et al. [21] or Piwowar-Sulej [3] have to be mentioned because they discuss pro-environmental behavior in the workplace. It has been acknowledged that by recognizing the manifestation of these factors in sustainable consumption behavior, companies can offer innovative solutions to increase their competitive advantage [22] in both personal and work 
environments. However, when summarizing current research findings, it is possible to conclude that there is a lack of focus on engagement as a predictor of sustainable consumption behavior.

While works of both marketing [15,23-26] and human resource management researchers [27-29] treat engagement in certain objects as a significant factor of relevant behavior or its consequences, the authors of this manuscript have chosen engagement in sustainable consumption as an independent variable that researchers have only recently started to investigate. It is important to note that often researchers $[11,13,30,31]$ use engagement to describe sustainable consumption, or a manifestation of pro-environmental behavior and do not examine it as a separate construct, or a behavioral factor. Only the results of studies on engagement in sustainable consumption by Kadic-Maglajlic et al. [15] and Piligrimienè et al. [26] are significant in terms of advancing research in the context of sustainable consumption behavior at home. Theoretical assumptions of Salciuviene [32] and Salciuviene et al. [33] are important in the context of researched engagement in sustainable consumption and behavior in the workplace. Thus, engagement in sustainable consumption is a relatively new and little researched concept that has yet to gain broader attention of researchers in the sustainability management literature.

Engagement in sustainable consumption might be exerted due to personal or social reasons, but this study holds that those are dependent on the environment (workplace or home) in which sustainable consumption takes place. However, there are no studies which combine and compare the engagement and sustainable consumption behavior of individuals in both environments. This study examines the above-mentioned environments and engagement in sustainable consumption as a factor of sustainable consumption behavior in a single study. Engagement in sustainable consumption is defined as a psychological state and is based on the multidimensionality of the construct (as in studies by Kadic-Maglajlic et al. [15] and Piligrimiene et al. [26]. In the context of the home and work environments, engagement in sustainable consumption is measured using five consumer engagement dimensions suggested by So et al. [34], which were empirically tested from both consumer and employee perspectives. Also, so far, it is not well understood why females and males exert different behaviors towards sustainable consumption [35]. Evidence suggests that both gender and age affect the sustainable behavior of individuals [36] but previous research produces conflicting findings as to whether older or younger individuals, females or males tend to exert higher sustainable consumption behavior. Especially in the case of sustainable consumption behavior, these differences are underrepresented and were seldom measured in earlier research.

Taking into consideration the limitations of the current research and the priorities of further studies, the manuscript addresses the following problem: How does engagement in sustainable consumption influence sustainable consumption behavior in different environments, that is, which dimensions of engagement in sustainable consumption can lead to sustainable consumption behavior at home and in the workplace? The main aim of this study is to uncover the relationship between the engagement in sustainable consumption and sustainable consumption behavior of individuals at home and in the workplace that is enabling companies to provide innovative solutions to advance sustainability management. The specific tasks are linked to (i) a theoretical and empirical justification of the main research design constructs-engagement in sustainable consumption, sustainable consumption behavior at home and sustainable consumption behavior in the workplace; (ii) uncovering gender and age differences in engagement in sustainable consumption-a sustainable consumption behavior link. By identifying sustainable consumption behaviors of individuals as employees in the workplace environment and as individual users at home and examining differences in gender and age of sustainable consumption behavior of individuals in both environments, this study seeks to contribute to the sustainability management literature. The original value of the studies presented in this manuscript is supported by the use of Social Learning and Collaborative Consumption Theory to theoretically and empirically justify engagement in sustainable consumption as a determining factor in sustainable consumption behavior at home and in the workplace. The study of the link between engagement in sustainable consumption and sustainable consumption behavior at home and in the workplace has been conducted involving working consumers in the UK, and, therefore, it complements the research 
base for sustainable consumption behavior in Western European countries. However, engagement in sustainable consumption is context dependent [37], which allows for further research to be conducted in relation to other cultural and economic contexts, consumption areas or product categories.

\section{Theoretical Background}

\subsection{Sustainable Consumption Behaviour at Home and in the Workplace: Engagement in Sustainable Consumption as a Factor}

Sustainable consumption behavior, its characteristics at home and in the workplace. Sustainable consumption behavior of individuals often becomes the object of scientists from management, psychology, sociology and natural sciences and this confirms its interdisciplinarity. When discussing the findings of these studies, it is important to note that the sustainable consumption field includes works conducted in ecologically conscious and socially conscious consumer behavior (e.g., [38]), pro-environmental behavior (e.g., [12,21]), environmentally responsible consumption (e.g., [17]), pro-social consumption behavior [15] or responsible sustainable consumer behavior [16] topics. As Pepper et al. [38] notes, a particularly large proportion of previous researchers examined their sustainable consumption works from the perspective of environmental psychology, where the term "ecologically conscious consumer behavior" was dominant. These researchers highlight the cognitive limitations of ecologically conscious behavior and emphasize the need for pro-social consumer behavior research based on the prospect of socially conscious consumer behavior. Block et al. [12] interpret pro-environmental behavior as synonymous behavior with sustainable consumption, linking their definitions with minimizing the negative impact of human behavior on the environment. Pro-environmental behavior is a rather popular subject for psychology research, as evidenced by works by Liobikiene and Poškus [39] or Whitburn et al. [13]. The Liobikienè and Poškus's [39] study answers the question of how specific environmental knowledge influenced pro-environmental behavior in private and public sphere, while the results of the Whitburn's et al. [13] study support the assumption that individuals' connection to nature may motivate their engagement in pro-environmental behavior. It should be noted that these authors identify pro-environmental behavior with ecological behavior, and the engagement of individuals as a separate research construct in this work is not considered; it is treated as a manifestation of pro-environmental behavior. In the context of interdisciplinary studies, the works of Theodori and Luloff [11] as well as Alcock et al. [14] need to be mentioned. Theodori and Luloff's [11] study integrates knowledge of management, sociology, psychology and agricultural sciences, the results of which empirically justify the hypothesis that individuals with different positions on environmental issues exhibit dissimilar levels of pro-environmental behaviors. The authors of this study use the term "engagement in sustainable consumption", both in the title of the article and in their study. However, as in the previously mentioned work of Whitburn et al. [13] and that of Theodori and Luloff [11], they describe the level of pro-environmental behavior and use pro-environmental behavior scales to measure engagement, but do not examine it as a separate construct. Alcock et al.'s [14] work uses psychology and environmental provisions to determine the link between nature, nature appreciation and pro-environmental behavior. To sum up studies of the interdisciplinary context, it is possible to agree with the statement by Blok et al. [12] that while many models have been developed to explain pro-environmental behavior, only a few of them have integrated altruism, empathy or other aspects of pro-social consumption behavior. This leads to the conclusion of previous studies examining pro-environmental behavior, which usually emphasizes the environmental or ecological dimension of sustainable consumption behavior.

The authors of this manuscript support the co-authors of the latest sustainable management (marketing) thematic works $[15,16]$, who believe that pro-environmental consumption behavior and pro-social consumption behavior are two different forms of sustainable consumption behavior. For example, Hosta and Zabkar [16] rightly propose a term of responsible sustainable consumer behavior, which emphasizes the environmental and social responsibility of sustainable consumption behavior. Therefore, for the purpose of holistic knowledge of sustainable consumption behavior, 
both pro-environmental or environmental and pro-social behavior indicators must be analyzed. This is the first principle that this manuscript underpins to examine the concept of sustainable consumption behavior. The second notable aspect, which is also linked to the holistic approach, is the understanding of sustainable consumption behavior as a three-phase process. In support of this position, while seeking a more detailed analysis of the phenomenon studied, i.e., engagement in sustainable consumption and sustainable consumption behavior, the authors of the research narrow the boundaries of the empirical study and choose one phase of sustainable consumption behavior for further analysis, that is, use behavior. The implementation of the first and second assumptions in the current study is enabled by the earlier findings in the literature on sustainable consumption behavior, and more specifically, by the phase of use behavior. Recommendations of Gupta and Agrawal [17] and Geiger et al. [18] are considered as the most important recommendations, which include not only environment friendly or conscious indicators, but also collaborative consumption indicators. In the context of the position chosen by the authors of the current manuscript, Geng et al. [19] and Geiger et al.'s [18] proposals concerning the characterization of the three phases of sustainable consumption behavior are equally relevant. The choice of one stage of sustainable consumption behavior is partly linked to the third assumption that underlines both the relevance and originality of this research-to analyze sustainable consumption behavior in both private life and work environments. The theoretical justification and empirical verification of sustainable consumption behavior construct in the workplace required separate attention for the findings by Blok et al. [12] and Wesselink et al. [21].

Sustainability management literature offers research on the sustainable behavior of individuals, but seldom refers to the separation of consumption behavior between home and work environments. For example, Gadeikiene et al. [6] examined both environments, but only at a theoretical level. In their work, "the main elements of conceptual model are organizational and private life setting and their interrelation drivers, which enable the sustainable consumption behavior spill-over from workplace to private life" ([6], p. 142). Given the theoretical nature of their research, the results cannot be compared and therefore, are not discussed in further stages of the Discussion and Results section.

When analyzing the spill-over effects in the literature, Muster and Schrader's [4] study can be mentioned. In their work, the authors theoretically justify the idea of a green work-life balance. To uncover the linkages between working and private life, the authors use the concept of environmental attitudes and behavior of employees. These authors note that in order to ensure green work-life balance among employees, their attitudes and behavior may be strengthened/activated in two directions. Muster and Schrader [4] focus only on the environmental aspects of sustainable consumption behavior and their theoretical insights are directed on the development of human resource management theory. As the later researchers (e.g., [5]) point out, work-life balance is a new perspective in green human resources management and is one of the five concepts that underpin the nature of this theory. Work-life balance and sustainable consumption linkages were also examined in Piligrimiene et al.'s [7] work, where work-life balance, or conflict, is interpreted as a predictor of sustainable consumption. Thus, work-life balance can be identified as a driver integrating sustainable consumption behavior in both personal life and workplace environments. Meanwhile, an overview of the current research suggests that majority of studies that analyze factors determining sustainable consumption behavior concentrate on individual environments.

Determinants of sustainable consumption behavior at home and in the workplace. The results of the studies, reviewed at the beginning of this section, highlight researchers' attention towards sustainable consumption behavior determinants in personal life, which are usually defined as pro-environmental behavior, as a connection to nature [13], nature appreciation [14], environmental knowledge [39] or positions on environmental issues [11]. It is possible to distinguish a separate group of authors who analyzed personal factors of the individual, such as knowledge, abilities, attitudes, values, norms, self-image or sociodemographic variables (e.g., [15,40-43]). After more than 15 years of comprehensive reviews on sustainable consumption or behavior studies, Joshi and Rahman [20] provide a list of personal, behavioral and socio-cultural factors affecting sustainable consumption 
decision-making. In their latest study on the topic of this manuscript, Hosta and Zabkar [16] highlight not only the importance of environmental consumption, but also the social dimension of sustainable consumption. These authors identify key variables, which are a part of the Theory of Planned Behavior, such as personal and social norms and perceived behavioral control, and treat those as antecedents of responsible sustainable consumer behavior. In addition, the results of their study reveal that these factors affect responsible sustainable consumer behavior through willingness to behave in an environmentally/socially responsible way.

Earlier research on factors contributing to sustainable consumption behavior in the workplace is also numerous, and their results confirm the importance of measurability, efficiency assessment and clarity of responsibilities of organizations [44], employee knowledge, private life practices, commitment, peers', in particular, managers' support, and their behavior role (e.g., [4,21,45-47]). A more structured approach is presented by Blok et al. [12], differentiating between internal and external factors of pro-environmental behavior in the workplace. In addition, these authors as well as other authors who study behavior in a personal environment, support their interpretation of factors' affects (especially internal) with the Theory of Planned Behavior. The work of Piwowar-Sulej [3], which synthesized factors determining such behavior and identified their manifestation through four levels of pro-environmental organizational culture, is exceptionally valuable in terms of researching pro-environmental employee behavior.

Engagement in sustainable consumption and its role in examining and encouraging sustainable consumption behavior at home and in the workplace. An analysis of factors contributing to sustainable consumption behavior in personal life and in the workplace suggests that until now, researchers have generally focused on the environmental dimension-related personal (more at home) and context (more in the workplace) factors and less frequently on variables reflecting social aspects. Moreover, the current examination reveals a lack of focus on engagement as a predictor of sustainable consumption behavior. This is considered to be a significant limitation of the findings of studies to date, which otherwise enable greater knowledge of the phenomenon of sustainable consumption behavior and the development of practices that promote it.

These assumptions are based on the earlier research findings of consumer engagement as a behavioral factor in the marketing literature [15,23-26,34,37,48]. Studies that explain the phenomenon of engagement are also identified in the research by human resource management researchers; however, the majority of these works involve research objects, such as work or an organization. Saks [27] focuses on supporting the antecedents and behavioral consequences of employee work or organizational engagement and their behavioral consequences, while Salanova and Schaufeli [28] investigate work engagement as the mediator between job resources and proactive behavior. From the conceptual point of view, the phenomenon of employee engagement and its different types of knowledge (work and organizational engagement) are synthesized in Motyka's [29] work. Motyka's work [29] is a systematic review of the scientific literature, which justifies the relationship between employee engagement and various categories of performance. Although the analysis of the results of both consumer and employee engagement studies provides sufficient evidence of engagement as a significant factor in the behavior, the engagement in sustainable consumption, which has been chosen as key independent variable in this manuscript, has only started to be investigated.

The synthesis of the literature allows us to conclude that authors examining sustainable consumption behavior in private life interpret consumer engagement as a manifestation of sustainable consumption behavior, that is, a certain result of consumer behavior. Indeed, consumer engagement in the context of sustainable consumption is analyzed with a focus on the consumption in a specific area, for example, energy [30,49], clothing [50-52], accommodation sector services [31] or food [53] consumption. For example, Bly et al. [50] and Armstrong et al. [51] examined sustainable fashion issues where they stress the importance of increasing consumer engagement in sustainable clothing consumption. In support of them, Connell and Kozar [52] examined the link between consumer knowledge and attitudes towards environmental problems in the production, consumption and 
realization stages of clothing and behavioral differences distinguishing between the levels of consumer engagement in sustainable consumption in the clothing sector and the barriers to their sustainable behavior. The results of studies conducted by Bly et al. [50] show that more effective results in promoting sustainable consumption behavior can be achieved by highlighting the benefits of engagement in sustainable consumption to the consumer through an emphasis on style, authenticity and the degree of future well-being, instead of the usual concerns about sustainability and the escalation of ethical concerns. Understanding of the factors determining consumer engagement and inclusion and a deeper understanding of consumer behavior in Gangale et al. [30] and Ellabban and Abu-Rab's [49] studies are considered as essential factors for achieving sustainable energy consumption in the future, while the study of Marzouk and Mahrous [54] is important for achieving sustainable water and energy consumption. Rist and Masoodian [55] use the behavior change model to examine sustainable energy consumption behavior and Ntanos et al. [56] examine the willingness to pay for renewable energy expansion.

The analysis of the literature that has been carried out suggests that consumer engagement in sustainable consumption is seen and analyzed as a manifestation of sustainable consumption behavior rather than as a psychological state, which is identified by investigating consumer engagement in brands, mobile applications or other types of marketing elements. In the first case, consumer engagement in sustainable consumption is synonymous with certain sustainable consumption behavior that might occur at different stages or areas of consumption. Fragmented studies of this type of behavior and their results can be seen in works of previously discussed authors (e.g., [13,30,31,50,51]). In the second case, engagement in sustainable consumption that is being examined as a psychological state, should be investigated in the search for links to the development of sustainable consumption behavior at different stages of consumption, that is, in order to answer the question whether/how sustainable consumption behavior depends on the engagement of consumers. In any case, as has been mentioned previously, sustainable consumption behavior should be examined in a holistic manner.

Based on this position of researchers, a relevant question then becomes the one that is related to the sustainable consumption context, or to the environment. According to Jackson [57], consumers are simply "stuck" in unsustainable consumption behavior due to daily routines, social norms and expectations, unsuitable initiatives, institutional barriers and limited choice. In addition, sustainable behavior of consumers depends not only on their own choices, but also on the opinions of the people surrounding them and their behavior [57]. Muster [58] also shares this view and argues that organizations to which consumers belong at certain stages in their lives play an important role in their personal lives as consumers. These organizations determine the daily routine and "assign" a person to a certain social group. However, Muster [58] sees opportunities to promote sustainable consumption behavior, as consumers who spend almost a third of their lives in these organizations can learn sustainable consumption habits while in these organizations and then transfer that behavior to their personal environment. Thus, companies, which engage with their employees in sustainable consumption initiatives at work, can thus contribute to the sustainable consumption behavior of these employees in their personal lives, that is, in their private environments.

The arguments identified above justify the choice of the authors of this manuscript to look at sustainable consumption behavior holistically and to analyze the behavior of sustainable consumption at work and at home as dependent variables. For this reason, a sample of working consumers has been chosen for the empirical study. To conceptualize and justify links of engagement in sustainable consumption - an independent variable - with sustainable consumption behavior at home and in the workplace, this study uses theories and findings of previous research. On the basis of these studies, works of Kadic-Maglajlic et al. [15], Piligrimiene et al. [26], Salciuviene [32] and Salciuviene et al. [33] can be directly attributed to the studies researching engagement in sustainable consumption-a sustainable consumption behavior link. Kadic-Maglajlic et al., [15] combines both pro-environmental and pro-social behavior forms of sustainable consumption behavior and Piligrimiene et al. [26] state that engagement in sustainable consumption by individuals depends on a variety of different factors, 
but do not differentiate between the environments (i.e., whether such engagement in sustainable consumption takes place at home or in the workplace). In addition, these authors select green product purchases as the consequence of engagement in sustainable consumption. Likewise, research on employee engagement in sustainable consumption in a workplace is rare and mostly reports factors influencing sustainable engagement rather than its consequences (but see Salciuviene [32] in terms of consumer behavior phases). Moreover, as it has been mentioned previously, those studies in the literature also treat consumer or employee engagement as behavior and do not analyze engagement in sustainable behavior as a separate construct in both environments.

In the light of the results of the previous studies, engagement in sustainable consumption in the manuscript is treated as a psychological state and is based on a multidimensional viewpoint (as in Kadic-Maglajlic et al., [15], Piligrimiene et al., [26] studies). In this case, it is measured using five dimensions of consumer engagement proposed by So et al. [34], such as Attention, Enthusiasm, Identification, Absorption and Interaction/Participation. Scales proposed by Calder et al. [59] and Hollebeek et al. [23] are also used in this study, but the scale proposed and tested by So et al. [34] is considered to be the main measurement scale for this study. Previous researchers $[15,26]$ used the most common three-dimensional consumer engagement construct found in the marketing literature, combining cognitive (attention), emotional (enthusiasm) and behavioral (interaction and participation) aspects of engagement in sustainable consumption. The choice of authors of the manuscript is based on a more accurate response to the five-dimensional scale of engagement in sustainable consumption and the fact that the scale by So et al. [34] has been empirically tested from both consumer and employee perspective in the tourism industry.

To address the engagement in sustainable consumption and sustainable consumption behavior phenomena at work and home environments, this research implements Social Learning Theory to hypothesize that engagement will positively influence sustainable consumption behavior at home and in the workplace environments. Social Learning Theory suggests that people can learn by experiencing things themselves or by observing others [60], whether they are psychically present, in front of the TV or virtually-in a video conference. Social learning is usually linked with rewards or punishments because through observations, people can see if others are rewarded or punished [61]. In other words, Bandura [62] in [61] suggests that social learning occurs not only through punishment and rewards but also by observing other people's behavior. For example, parents are observed by their children, teenagers observe celebrities on TV or parents monitor their colleagues in the workplace. Those people who could be observed should cause observers to learn from their behavior and follow it with their own actions. This research holds that engagement in sustainable consumption is an engagement of an individual with pro-social decisions, which an individual makes at home and in the workplace environments when deciding to engage in sustainable behavior. Further, this research defines sustainable consumption behavior as environmentally friendly behavior, which is based on environmentally responsible use activities by an individual in both workplace and home environments.

Social Learning Theory may aid in explaining the positive influence of collaborative learning [60] or collaborative consumption [63] on sustainable consumption behavior in both environments because the theory suggests that individuals learn by going through the experiences themselves or by observing other people performing various activities and learning from the behavior of other people [60]. Also, in today's competitive environment, companies attempt to learn from each other. They also tend to conform with the "society boundaries and the social values associated with or implied by their activities and the norms of acceptable behavior in the larger social system of which they are part" [64] (p.122). For example, Miller and Karakowsky [65] suggest that at work individuals use knowledge and gain information from other team-members and this aids their performance in the workplace: individuals who get feedback and alter their performance achieve better results. Also, such knowledge and feedback seeking behavior is gender-dependent [65]. In this research, it is expected that if engagement in sustainable consumption may provide a suitable environment for pro-social employee behavior, 
then engagement in sustainable consumption generates higher sustainable consumption behavior at home and in the workplace environments.

Based on the above, we raise the following hypothesis:

Hypothesis 1 (H1). Engagement in sustainable consumption will positively influence the sustainable consumption behavior of individuals (a) at home and (b) in the workplace.

\subsection{Gender and Age Differences in Engagement in Sustainable Consumption and Sustainable Consumption} Behaviour Practices

Previous literature reports different behaviors of females and males when it comes to sustainable consumption (e.g., [66-71]). For example, females drive less in order to preserve the environment [72]. Females also tend to shop more sustainably in comparison to males [73] and females tend to recycle more compared to males [74]. Hence, it is vital to identify the reasons behind such behavioral differences in the sustainable consumption behavior by gender in personal life and workplace environments. For instance, Shim et al. [75] suggest that such differences in female versus male behavior could be attributed to decision-making differences. Remenova and Jankelova [76] state that decision-making, acquiring, processing and using information are used by individuals to make their final decision. Shim et al. [75] state that males tend to make functional decisions, while females make socially oriented decisions. Such decision-making styles may contribute to the different sustainable behaviors of individuals in terms of gender. However, a contradicting finding by Pinto et al. [77] states that personal reasons are more important for females when shopping for sustainable products, while males purchase products and services for social reasons. To clarify the inconsistency of gender roles in the literature, we hypothesize the following:

Hypothesis 2 (H2). Females will behave differently from males in terms of sustainable consumption behavior (a) at home and (b) in the workplace.

Next, the sustainability management literature on age differences pertaining to the environmentally friendly behavior is limited. Therefore, this research draws on the decision-making literature. Previous research suggests different behaviors of younger versus senior individuals (e.g., [11,78,79] in [80] (p. 206)). For example, younger individuals tend to focus on their career and family building while older people are free to experiment with healthy lifestyles, to pursue their education or engage in various forms of helping behavior [80]. Younger individuals are less concerned with the use stage of consumption behavior and focus more on the acquisition stage [81]. Earlier studies report that older people are more willing to engage in voluntary work or unpaid work to help others [80] while younger people tend to spend most of their time taking care of their young families and take paid work to support themselves [80]. In other words, older people might have more time for themselves and, therefore, engagement in sustainable consumption or other environmentally friendly activities might be easier as their families are grown up. Further, previous research suggests that younger individuals tend to think less about consequences of products and services they use on the environment as compared to older individuals [82]. This might be due to several reasons; however, the explanation of the age role in the sustainable behavior of individuals remains unclear. Therefore, we raise the following hypothesis:

Hypothesis 3 (H3). Older individuals will behave differently in comparison to younger individuals regarding sustainable consumption behavior (a) at home and (b) in the workplace.

\section{Research Objective, Method and Data}

The aim of this empirical study is twofold: first, to identify the effects of engagement in sustainable consumption on sustainable consumption behavior of individuals; second, to uncover whether any differences can be identified between females and males as well as between younger and older individuals regarding sustainable consumption behavior in both workplace and home environments. 
An online questionnaire comprised four sections. Section A contained items on engagement in sustainable consumption (e.g., "I follow sustainable consumption principles passionately"). engagement in sustainable consumption is operationalized through five-dimensions, namely, attention, enthusiasm, identification, absorption, interaction/participation. Items to measure engagement in sustainable consumption were adapted from So et al. [34], Calder et al. [59] and Hollebeek et al. [23]. Section B measured sustainable consumption behavior (use phase) at home. Examples of such items are as follows: "When using things/products, try to reduce waste"; "Whenever possible, I borrow things/means from others". Items for this section were adapted from Littleford et al. [83], Blok et al. [12], Geng et al. [19] and Gupta and Agrawal [17]. Section C measured sustainable consumption behavior (use phase) in the workplace. Sample items are as follows: "I usually eat fast food in the workplace $(\mathrm{R})^{\prime}$, "I take care to print/copy double sided to save paper". Items for this section were adapted from Littleford et al. [83], Blok et al. [12], Geng et al. [19], Gupta and Agrawal [17] and Geiger et al. [18]. Items were measured using 7-point Liker scale (1-completely disagree, 7-completely agree). The final section contained socio-demographic questions (i.e., gender, age, marital status and company's profile). A full list of items along with demographics is presented in Appendix A.

A questionnaire was distributed via various sustainable consumption-related portals on Facebook's platform in the year 2019. A sample of 407 adult respondents who work in the UK private and public sectors comprised the sample for this study.

Data was analyzed using SPSS statistical package. Exploratory Factor Analysis, correlation, $t$-tests and regression analyses were utilized to analyze the data collected via online questionnaires.

\section{Results and Discussion}

\subsection{Characteristics of Respondents and Exploration of the Research Constructs}

Socio-demographic characteristics of respondents. Females comprise 67.3 percent of the sample. The sample age varies, with the majority of the respondents' ages being 20-40 years old. With regard to the family's life cycle, 31.9 percent of respondents are bachelors, while 32.4 percent of respondents either have a partner or are married with children. Nearly 42 percent of respondents work in a private sector for approximately 69 percent of the UK-based companies.

Further, exploratory factor analysis was performed for the following constructs under investigation: engagement in sustainable consumption, sustainable consumption behavior at home and sustainable consumption behavior in the workplace.

Engagement in sustainable consumption. Exploratory factor analysis was performed on 22 items of engagement (Table 1). These items were adapted from So et al. [34], Calder et al. [59] and Hollebeek et al. [23] and were developed or tested in the tourism sector and engagement with a website or a brand in the context of social media. Based on these items, three factors were extracted for engagement, namely, Enthusiasm and Attention (FE1), Identification and Absorption (FE2) and Participation/Interaction (FE3), which is contrary to the theoretically justified five-dimensional construct of engagement in sustainable consumption. To compare these findings with previous studies, for example, Vivek et al. [37] identify three dimensions in their findings: Conscious Attention, Enthused Participation and Social Connection. These authors underline Conscious Attention in their research, which they define as an individual's willingness to interact in terms of engagement and suggest that this factor explains majority of variance, therefore, is the most important factor in the context of retailing. This finding is similar to our finding, since the Enthusiasm and Attention factor explains nearly $30 \%$ of variance in the context of sustainability. In Vivek et al.'s [37] study, however, the Social Connection factor produced insignificant findings before the context of their study was introduced. After testing items in the context of retailing, Vivek et al. [37] found that Conscious Attention and Social Connection did not differ significantly, but Social Connection did. In our study, the Participation/Interaction factor is similar to that of Social Connection in Vivek's et al.'s [37] study and explains nearly $20 \%$ of variance. Further, in this study, one factor combines Enthusiasm with Attention and Identification is linked to 
Absorption, while Participation/Interaction can be separated as a different factor. A combination of Enthusiasm and Attention as well as Identification and Absorption into separate factors is an interesting finding of this study that has not been reported before. Next, our results may also be compared to So et al.'s [34] findings, where Enthusiasm and Attention dimensions play the most important role in the context of the tourism industry. Further, Kadic-Maglajlic et al. [15] examined pro-social and pro-environmental engagement of youth and arrived at three dimensions, that is, Conscious Attention, Enthused Participation and Social Connection, as in Calder et al. [59] and Vivek et al. [37]. Apparently, their factor structure is different from the factor structure of this study; however, the meaning of the factors is similar. Finally, classic cognitive, emotional and behavioral dimensions were identified in Piligrimiene et al.'s [26] study, but their context of testing factors was linked to the purchasing of green products. Our context is not related to any specific product or service acquisition and focuses on the use phase of sustainable consumption behavior, therefore the discussion of factors and their items is limited to very few earlier works conducted on engagement in sustainable consumption in the context of the sustainability management area.

Table 1. Exploratory Factor Analysis for engagement in sustainable consumption ${ }^{1}$.

\begin{tabular}{cccc}
\hline Factor & No of Items & $\begin{array}{c}\text { Range of Factor } \\
\text { Loadings }\end{array}$ & $\begin{array}{c}\text { Variance Explained by } \\
\text { Each Factor \% }\end{array}$ \\
\hline FE1 Enthusiasm and Attention & 12 & $0.549-0.750$ & 28.19 \\
FE2 Identification and Absorption & 6 & $0.426-0.738$ & 20.94 \\
FE3 Participation/Interaction & 4 & $0.618-0.751$ & 18.24 \\
\hline
\end{tabular}

${ }^{1} \mathrm{KMO}-0.935$, Bartlett's test of sphericity $p<0.05$, Total variance explained, \%-67.383, Cronbach alfa-0.959.

Sustainable consumption behavior at home. Again, exploratory factor analysis was performed on 10 items for the construct of sustainable consumption behavior at home (Table 2). As it has been mentioned, the current study only focuses on one phase of sustainable consumption behavior, that is, use behavior, and, therefore, specific items were selected to measure this phase in the home environment. Two factors were extracted for sustainable consumption behavior at home, namely Sustainability principles through saving initiatives (FH1) and Borrowing and sharing things at home (FH2). To the best of our knowledge, there are no studies conducted that report factors of the use phase of sustainable consumption behavior in a home environment. The closest study that reports two types of behavior in general is that of Kadic-Maglajlic et al. [15], who examined pro-environmental and pro-social behavior in light of general consumption behavior without differentiating three phases, that is, acquisition, use and disposal.

Table 2. Exploratory Factor Analysis for sustainable consumption behavior at home ${ }^{1}$.

\begin{tabular}{cccc}
\hline Factor & No of Items & $\begin{array}{c}\text { Range of Factor } \\
\text { Loadings }\end{array}$ & $\begin{array}{c}\text { Variance Explained by } \\
\text { Each Factor \% }\end{array}$ \\
\hline $\begin{array}{c}\text { FH1 Sustainability principles through } \\
\text { saving initiatives at home }\end{array}$ & 5 & $0.572-0.826$ & 30.94 \\
FH2 Borrowing and sharing things at home & 5 & $0.446-0.870$ & 25.79 \\
\hline
\end{tabular}

${ }^{1}$ KMO-0.845, Bartlett's test of sphericity $p<0.05$, Total variance explained, \%-56.735, Cronbach alfa-0.856.

Sustainable consumption behavior in the workplace environment. Further, exploratory factor analysis was performed on the 11 items measuring use behavior in the workplace by individuals as employees (Table 3). As it has been mentioned, the current study only focuses on one phase of sustainable consumption behavior, that is, use behavior; therefore, specific items were selected to measure this phase in the workplace. Two factors were extracted, namely Sustainability principles through saving initiatives in the workplace (FW1) and Avoiding plastic dishes and fast food in the workplace (FW2). Our findings mirror those of Zibarras et al. [45], who investigated organizations in the UK and found out about environmental initiatives offered by companies, which encourage employees to use public 
transport, print double sided papers, keep all PCs switched off for the night and have a "lights-out" policy in place.

Table 3. Exploratory Factor Analysis for sustainable consumption behavior in the workplace environment ${ }^{1}$.

\begin{tabular}{cccc}
\hline Factor & No of Items & $\begin{array}{c}\text { Range of Factor } \\
\text { Loadings }\end{array}$ & $\begin{array}{c}\text { Variance Explained by } \\
\text { Each Factor \% }\end{array}$ \\
\hline $\begin{array}{c}\text { FW1 Sustainability principles through } \\
\text { saving initiatives in the workplace }\end{array}$ & 9 & $0.538-0.812$ & 43.89 \\
$\begin{array}{c}\text { FW2 Avoiding plastic dishes and fast food } \\
\text { in the workplace }\end{array}$ & 2 & $0.654-0.857$ & 14.99 \\
\hline
\end{tabular}

${ }^{1} \mathrm{KMO}-0.895$, Bartlett's test of sphericity $p<0.05$, Total variance explained, $\%-58.873$, Cronbach alfa- 0.880 .

\subsection{Relationships among Engagement in Sustainable Consumption and Sustainable Consumption Behaviour at} Home and in the Workplace

At first, a correlation test was performed to check for the relationships among variables. All correlation coefficients were weak (0.0-0.3), medium (0.4-0.6) or strong (0.7-0.9) (Table 4).

Table 4. Correlation matrix.

\begin{tabular}{|c|c|c|c|c|c|c|c|}
\hline Title 1 & 1 & 2 & 3 & 4 & 5 & 6 & 7 \\
\hline FE1 Enthusiasm and Attention & 1 & & & & & & \\
\hline FE2 Identification and Absorption & $0.726 * *$ & 1 & & & & & \\
\hline FE3 Participation/Interaction & $0.706^{* *}$ & $0.739 * *$ & 1 & & & & \\
\hline $\begin{array}{l}\text { FH1 Sustainability principles through saving } \\
\text { initiatives at home }\end{array}$ & $0.723 * *$ & $0.510 * *$ & $0.535^{* *}$ & 1 & & & \\
\hline FH2 Borrowing and sharing things at home & $0.578 * *$ & $0.409^{* *}$ & $0.463 * *$ & $0.606^{* *}$ & 1 & & \\
\hline $\begin{array}{l}\text { FW1 Sustainability principles through saving } \\
\text { initiatives in the workplace }\end{array}$ & $0.709 * *$ & $0.480^{* *}$ & $0.497^{* *}$ & $0.821 * *$ & $0.652 * *$ & 1 & \\
\hline $\begin{array}{l}\text { FW2 Avoiding plastic dishes and fast food in } \\
\text { the workplace }\end{array}$ & $0.345^{* *}$ & $0.186^{*}$ & $0.105^{*}$ & $0.340 * *$ & $0.372^{* *}$ & $0.392 * *$ & 1 \\
\hline
\end{tabular}

Engagement in sustainable consumption and Sustainable consumption behavior at home. To test whether engagement influences sustainable consumption behavior at home (H1a), a regression analysis was performed. The $\mathrm{R}$ value was equal to 0.733 , suggesting a strong and positive relationship between engagement and sustainable consumption behavior at home. The $\mathrm{R}$ square value was equal to 0.537 , suggesting that 53.7 percent of variance in sustainable consumption behavior at home is explained by engagement.

The ANOVA results also suggest that the regression model has a good fit and, therefore, is a good predictor of the dependent variable (sustainable consumption behavior at home), with the $p$ value being significant at $p<0.001$. Although engagement (independent variable) comprises three dimensions and all three could predict the dependent variable (i.e., sustainable consumption behavior at home), Enthusiasm and Attention (FE1) $(\beta=0.705, p<0.001)$ and Participation/Interaction (FE3) ( $\beta=0.127, p<0.001)$ predict the sustainable consumption behavior at home. For example, an increase of Enthusiasm and Attention by one level will increase the sustainable consumption behavior at home by 70.5 percent.

The above results of our study, that is, engagement in sustainable consumption and sustainable consumption behavior at home and in the workplace environments, may be compared to findings of earlier studies in the literature conducted on engagement in sustainable consumption and general consumer, or employee, sustainable consumption behavior. For example, Kadic-Maglajlic et al. [15] found that engagement in sustainable consumption was positively related to the pro-environmental and pro-social behavior of consumers in general. Further, Piligrimiene et al. [26] found that engagement in sustainable consumption is related to general consumption behavior. Next, our findings mirror previous findings of Kadic-Maglajlic et al. [15] as well as those of Piligrimiene et al. [26], as we found that 
engagement in sustainable consumption influences use behavior and our study measures engagement in sustainable consumption of working consumers in two environments: at home and in the workplace. We treated the "engagement in sustainable consumption" as a separate construct comprising several dimensions; therefore, we can conclude that engagement in sustainable consumption affects the use phase of sustainable consumption behavior through, for example, Enthusiasm and Attention at home environment.

Engagement in sustainable consumption and Sustainable consumption behavior in the workplace. Regression analysis was performed to test whether engagement in sustainable consumption influences sustainable consumption behavior in the workplace $(\mathrm{H} 1 \mathrm{~b})$. The R value was equal to 0.644 , suggesting a strong and positive relationship between engagement and sustainable consumption behavior in the workplace. The $\mathrm{R}$ square value was equal to 0.414 , suggesting that 41.4 percent of variance in sustainable consumption behavior in the workplace is explained by engagement. The ANOVA results also suggest that the regression model has a good fit and, therefore, it is a good predictor of the dependent variable (sustainable consumption behavior in the workplace) with a $p$ value that is significant at $p<0.001$. Although engagement in sustainable consumption comprises three dimensions and all three could predict the dependent variable (i.e., sustainable consumption behavior in the workplace), again, Enthusiasm and Attention (FE1) $(\beta=0.783, p<0.001)$ and Participation/Interaction (FE3) $(\beta=0.135, p<0.001)$ predict the sustainable consumption behavior in the workplace. For instance, an increase of Enthusiasm and Attention (FE1) by one level will increase the sustainable consumption behavior in the workplace by 78.3 percent. Our results in the workplace in the context of sustainability can be compared to So et al.'s [34] study suggesting similar findings in the tourism industry. In their study, the authors also recommend focusing on enthusiasm and attention first when communicating with the customers in the context of hotel and airline industries.

\subsection{Gender Differences}

Independent samples $t$-test between females and males was performed to test $\mathrm{H} 2 \mathrm{aandH} 2 \mathrm{~b}$ and identify whether statistically significant differences exist between two groups regarding sustainable consumption behavior at home ( $\mathrm{H} 2 \mathrm{a})$ and in the workplace $(\mathrm{H} 2 \mathrm{~b})$. The results suggest that females have higher sustainable consumption behavior scores than males in both environments at home apropos both factors. Sustainability principles through saving initiatives at home (FH1) was slightly higher among females (females $\mathrm{M}=5.79, \mathrm{SD}=1.03$ versus males $\mathrm{M}=5.35, \mathrm{SD}=1.18$ ), and a significant statistical difference was detected $\left(\mathrm{t}_{231.59}=3.68, p<0.01\right)$. Borrowing and sharing things at home (FH2) was also higher among females (females $\mathrm{M}=4.91, \mathrm{SD}=1.07$ versus males $\mathrm{M}=4.50, \mathrm{SD}=0.92$ ) and a significant statistical difference between females and males was detected $(\mathrm{t}(405)=3.82, p<0.01)$.

Sequentially, in the workplace environment, pertaining to Sustainability principles through saving initiatives in the workplace (FW1), females exhibited somewhat more frequent behavior than males (females $\mathrm{M}=5.70, \mathrm{SD}=1.08$ versus males $\mathrm{M}=5.37, \mathrm{SD}=0.92$ ) and a significant statistical difference was detected $(\mathrm{t}(361)=2.92, p<0.05)$, while regarding Avoiding plastic dishes and fast food in the workplace (FW2), again, females exhibited stronger behavior than males (females $\mathrm{M}=6.11, \mathrm{SD}=0.97$ versus males $\mathrm{M}=5.52, \mathrm{SD}=1.11)$ and a significant statistical difference was detected $\left(\mathrm{t}_{206.87}=4.89\right.$, $p<0.05)$. In other words, statistically significant differences were unveiled between female and male sustainable consumption behavior pertaining to four factors mentioned above, meaning that females tend to exhibit sustainable consumption behavior at home more often than males do in terms of borrowing and sharing things at home as well as following the sustainability principles through saving initiatives at home.

Pertaining to the explanation of the first significant finding between females and males apropos Sustainability principles through saving initiatives at home (FH1), most likely females and males behave differently in terms of using things in moderation when trying to reduce waste along with water and electricity saving initiatives at home. This happens due to financial reasons, as saving water and electricity is reflected in their utility bills and those saving are passed on to buy other important 
products and services for those households, which is mostly done by females. Moreover, previous research suggests that more women are less likely to be employed full-time at all ages [80] and the sample comprises a lot of women, thus financial constrains might be a reasonable explanation for this significant finding across both groups of individuals for this factor. Also, this result is different from previous findings in the literature where no significant differences were found between females and males in their sustainable behavior by $\mathrm{Ng}$ and Burke [84].

Next, a possible explanation for the second significant finding regarding Borrowing and sharing things at home (FH2) might be that since males are less frugal than females [85], men tend to own gadgets like mobile phones, computers or TVs and, therefore, the need to borrow from or share the devices with other members within their immediate family is lower in comparison to females. Conversely, females might play with their young children more often than men at home, and the need for sharing toys or digital equipment becomes greater (e.g., giving a mobile phone to a toddler to play with).

Further, the results suggest that females and males differ in their sustainable consumption behavior in the workplace, where females exhibit higher sustainable consumption behavior than males in that environment for both Sustainability principles through saving initiatives in the workplace (FW1) and Avoiding plastic dishes and fast food in the workplace (FW2). This finding could be explained by Social Learning Theory. For example, males tend to learn only when they perform a male-oriented task [65]. Since environmentally-related concerns and shopping for environmentally-related products are mainly perceived as a female-oriented task $[65,86-88]$, it is possible that males are less willing to learn from their work-related surroundings about sustainable consumption behavior (e.g., printing double sided paper, sharing with others or borrowing from others, switching lights off in the office and saving water and trying to reduce waste as much as possible and contribute to landfill preservation management) because they may fear losing their masculine image in front of other male or female peers or are not willing to sacrifice their ego [65] in the workplace environment. To educate males about sustainable saving initiatives in the workplace and explain harmful effects that fast food has on their health, online games may be offered to educate them about what contributions employees can make to environment preservation and to their health if they exert sustainable consumption behavior in the workplace. Also, a communication platform for integrating knowledge about sustainable consumption behavior might be created for employees in the workplace. Money that employees would gain from contributing to environment-related initiatives such as saving water, electricity and paper with ink at work could be passed on to individuals by a company as an online voucher to subsidize fresh food options in canteens onsite and to encourage males to use fresh food more frequently and reduce their use of fast food options along with plastic dishes.

\subsection{Age Differences}

An independent sample $t$-test between two groups of participants (under 38 and over 38 years old) was performed to test $\mathrm{H} 3 \mathrm{a}$ and $\mathrm{H} 3 \mathrm{~b}$ and to identify whether statistically significant differences exist between two age groups apropos sustainable consumption behavior at home (H3a) and in the workplace environment (H3b). A split for age of 38 years old was chosen based on the literature and it refers to 'Prime age adults in their $40 \mathrm{~s}$ ' versus 'Second age adults in their $50 \mathrm{~s}$ ' and older [80]. The results suggest that older individuals exert stronger sustainable consumption behavior than younger ones pertaining to Sustainability principles through saving initiatives at home (FH1) (over $38 \mathrm{M}=5.85, \mathrm{SD}=0.97$ versus under $38 \mathrm{M}=5.46, \mathrm{SD}=1.18$, a significant statistical difference was detected: $\left.\mathrm{t}_{400.58}=-3.63, p<0.01\right)$. This finding is contrary to the results in the literature stating that younger individuals are more likely to exhibit responsible product purchasing behavior $[11,89]$. Such a contrary finding might be explained by the data collection context (the data for this study was collected in the UK and the context is different from India). Also, a study by Gandhi and Kaushik [89] examines purchasing behavior in general, while this result is significant for the consumption behavior in the context of home environment. However, these results can be compared to the study of Kreuzer et al. [81] 
who also found that use behavior is less important for young consumers in the context of sustainable consumption of fashion and food due to their parents purchasing the majority of products for them, especially for those who still live with their parents and rely on them to acquire food items for their household consumption.

To explain the above finding of differences in individuals' behavior by age apropos Sustainability principles through saving initiatives at home (FH1), this study used Social Learning Theory. According to Social Learning Theory, individuals learn when they observe behavior of other people. The literature suggests that individuals do not search for information about sustainable consumption practices but rely instead on internal sources of information [90]. In this case, individuals who belong to the over 38 years group may have more sustainable consumption related experience and higher sustainability-related awareness in comparison to younger adults (under 38 years old). In the older group, nearly 50 percent of all adults live in a family and have children and 22 percent have a partner, therefore social learning is possible through socialization. For example, social learning can happen through the impact of other members of the household, or conversations with other parents in children's schools and neighbors because older people, especially seniors, are keen socializers and eager to learn about the topics important for today's society, i.e., sustainable consumption and environmental preservation. Contrary to individuals in the older group, younger persons have less opportunities to observe sustainability-related behavior of other household members in the home environment because nearly 40 percent of them are still bachelors. Another explanation for the differences in sustainable consumption behavior at home by age might be related to financial constraints. The older group of individuals may have higher financial liabilities, while younger individuals live separately from their extended families and the majority of them (over 80 percent) do not have children at home and, therefore, have fewer financial responsibilities in comparison to individuals who belong to the older group.

Further, no statistically significant differences between two age groups was detected apropos another factor, namely, Borrowing and sharing things at home (FH2). Collaborative Consumption Theory is used to explain this insignificant finding. As Collaborative Consumption Theory suggests, collaborative use of gadgets in the home environment might be the best indicator of social learning, since younger individuals do not differ in their borrowing and sharing initiatives at home in comparison to older individuals. Younger people can reap the benefits of collaborative consumption through sharing and borrowing means from their friends and extended family, while borrowing and sharing naturally happens in the older group of individuals, enabling them to exhibit sustainable consumption behavior at home.

Next, no statistically significant differences were found between two groups of individuals by age in the workplace environment pertaining to Sustainability principles through saving initiatives in the workplace (FW1), but Avoiding plastic dishes and fast food in the workplace factor (FW2) yielded significant results (over $38 \mathrm{M}=6.01, \mathrm{SD}=0.98$ versus under $38 \mathrm{M}=5.76, \mathrm{SD}=1.09, \mathrm{t}(361)=-3.02$, $p<0.05)$. Although the first finding requires further investigation, the lack of statistically significant differences might be explained by the context of the study, as the data has been collected in the UK. Majority of companies and organizations in the UK have corporate social responsibility strategies in place and employees usually have relatively high awareness about sustainable consumption practices in the workplace. For example, both groups of younger and older employees behave similarly in terms of printing double sided, saving water and switching off their computers along with using means in moderation and sharing or borrowing means when they need them instead of buying new ones in their workplace. Such behavior of individuals might also be reflected in the status they occupy within an organization and their enhanced perceptions of responsibility to the environment. The higher the status, the more natural it would be that an individual would demonstrate saving patterns within the organization because of the alertness that they hold about the company's corporate social responsibility and, therefore, they might have more knowledge about how sustainable consumption behavior at work contributes to the environment preservation and to their own health. 
Generalizing both theoretical research findings and discussion, we offer Figure 1. Figure 1 provides an overview of hypothesized relationships, theoretical support based on Social Learning Theory, Collaborative Consumption Theory and previous empirical literature in tourism, brand management, sociology and psychology fields along with the current study's findings.

\begin{tabular}{|c|c|c|}
\hline $\begin{array}{l}\text { Theoretical underpinning of } \\
\text { proposed relationship or } \\
\text { outcome of the study }\end{array}$ & Proposed relationship & Outcome of this study \\
\hline $\begin{array}{l}\text { Social Learning Theory; } \\
\text { Collaborative Consumption } \\
\text { Theory; } \\
\text { Gadeikiene et al. [6], } \\
\text { Kadic-Maglajlic et al. [15], } \\
\text { Piligimiene et al. [26] }\end{array}$ & $\begin{array}{l}\text { H1: Engagement in } \\
\text { sustainable consumption } \\
\text { will positively influence } \\
\text { sustainable consumption } \\
\text { behavior of individuals (a) } \\
\text { at home and (b) in the } \\
\text { workplace. }\end{array}$ & $\begin{array}{l}\text { A new finding for engagement in } \\
\text { sustainable consumption } \\
\text { influences on sustainable } \\
\text { behavior at home and in the } \\
\text { workplace. For example, } \\
\text { engagement affects use behavior } \\
\text { through enthusiasm and } \\
\text { attention in both home and } \\
\text { workplace environments, similar } \\
\text { to previous findings of So et al. } \\
\text { [34] and Vivek et al. [37]. }\end{array}$ \\
\hline $\begin{array}{l}\text { Social Learning Theory; } \\
\text { Shim et al. [75]; } \\
\text { Remenova and Jankelova [76]; } \\
\text { Pinto et al. [77] }\end{array}$ & $\begin{array}{l}\text { H2: Females will behave } \\
\text { differently from males in } \\
\text { terms of sustainable } \\
\text { consumption behavior (a) } \\
\text { at home and (b) in the } \\
\text { workplace. }\end{array}$ & $\begin{array}{l}\text { A new finding for gender } \\
\text { differences at home and in the } \\
\text { workplace. Specifically, males } \\
\text { are less engaged into sustainable } \\
\text { consumption at home and in the } \\
\text { workplace than females. }\end{array}$ \\
\hline $\begin{array}{l}\text { Social Learning Theory; } \\
\text { Collaborative Consumption } \\
\text { Theory; } \\
\text { James et al. [78] } \\
\text { Moen and Flood [80] } \\
\text { Burke et al. [82] }\end{array}$ & $\begin{array}{l}\text { H3: Older individuals will } \\
\text { behave differently in } \\
\text { comparison to younger } \\
\text { individuals regarding } \\
\text { sustainable consumption } \\
\text { behavior (a) at home and } \\
\text { (b) in the workplace. }\end{array}$ & $\begin{array}{l}\text { A new finding for age } \\
\text { differences at home and in the } \\
\text { workplace. Specifically, older } \\
\text { and younger generations differ } \\
\text { in their use behavior regarding } \\
\text { sustainability-related savings at } \\
\text { home and avoiding plastic } \\
\text { dishes and fast food in the } \\
\text { workplace. }\end{array}$ \\
\hline
\end{tabular}

Figure 1. Theoretical underpinning, proposed relationships and findings of the current study.

Generalizing empirical findings of this study, it can be stated that some of the empirical results are supported by previous findings and some of the results are new to this study that have not been reported before in earlier research. For example, our findings suggest that Enthusiasm and Attention are the most important factors when making decisions at home and in the workplace, while the dimension of Identification and Absorption requires further research. Such a finding suggests that if working consumers behave sustainably in the workplace environment, it is likely they will behave in the same manner at home and vice versa. These findings may provide the basis for the transfer of initiatives from one environment to another.

\section{Conclusions}

In a competitive environment, employee environmentally friendly behavior is becoming a sustainable advantage for innovative companies, which offer innovative solutions to their employees and other stakeholders. This study aimed to examine effects of engagement in sustainable consumption on sustainable consumption behaviors of individuals and identify gender and age differences in the 
workplace and home environments. Social Learning Theory and Collaborative Consumption Theory have been used to hypothesize the above relationships and support the explanation of the study's findings. By researching relationships of engagement in sustainable consumption and sustainable consumption behavior as well as recognizing gender and age variations in sustainable consumption behavior at home and in the workplace environments, this research contributes to overcoming the gap in the sustainability management literature.

Pertaining to the effects of engagement in sustainable consumption, it has been concluded that it comprises three dimensions, namely, Enthusiasm and Attention, Identification and Absorption and Participation/Interaction. Further, two dimensions of sustainable consumption behavior in each context (home and workplace) were identified, namely, Sustainability principles through saving initiatives at home and Borrowing and sharing things at home. In the context of the workplace environment, Sustainability principles through saving initiatives in the workplace and Avoiding plastic dishes and fast food in the workplace factors were revealed. After performing regression analysis, it was uncovered that a change in engagement in sustainable consumption through Enthusiasm and Attention by one level can increase the employee sustainable consumption behavior at home and in the workplace by more than 70 percent.

In terms of gender differences, it was found that males are less inclined to get engaged into sustainable consumption in both environment (home and work) in comparison to females. Social Learning Theory and Collaborative Consumption Theory are used to explain such behavior. Also, it has been noted that males are willing to learn more when a masculine task is presented to them, while sustainable consumption behavior that is associated with shopping for environmentally friendly products and saving the environment is considered to mainly be a task for females. Thus, it is concluded that males tend to avoid female-oriented tasks because they attempt to preserve their macho ego and fearless image [65].

Apropos age differences, this study concludes that sustainability principles that are applied as saving initiatives at home differ among individuals by age in the two groups under investigation. Older (over 38 years old) individuals tend to implement more sustainability-related savings at home in comparison to younger individuals (under 38 years old).

Since no significant differences by age were accounted for sustainability principles to be applied in the workplace, this factor also requires further investigation. Moen and Flood [80] refer to public engagement that they understand as an engagement in a socially recognized role to assist others in society but not family members. Such an engagement differs with age since older people retire and can no longer serve in a socially recognized role, therefore an investigation of these roles in future studies would also aid the explanation of currently insignificant results for this study apropos sustainability principles in the workplace. However, there are differences between two groups of individuals by age regarding Avoiding plastic dishes and fast food in the workplace behavior. Older (over 38 years old) individuals tend to avoid plastic dishes more than younger individuals (under 38 years old).

\subsection{Theoretical Implications}

Marketing literature offers a variety of studies on pro-environmental behavior, yet the attitude-behavior gap exists among consumers as they tend to have positive attitudes towards purchasing green products but when it comes to consumption, they usually buy more than they really need for their households.

As it has been mentioned in the literature review, the majority of earlier studies use the term engagement but do not examine the effect of it on sustainable consumption behavior, that is, they treat it as one construct and do not differentiate between engagement in sustainable consumption and sustainable consumption behavior. Moreover, previous research mainly focuses on the environmental, or ecological, dimension of sustainable consumption behavior only and does not integrate the pro-social element of sustainable consumption behavior. In other words the majority of researchers do not use the holistic approach to examine engagement in sustainable consumption in the context of sustainability in 
their studies. Further, no studies compared work and private life environments in terms of engagement in sustainable consumption. This study focuses on both home and work environments and examines engagement in sustainable consumption-a sustainable consumption behavior link.

Hence, the current study offers an interesting picture on the role of engagement in sustainable consumption and use behavior of individuals at home and workplace environments. Given that both Social Learning and Collaborative Consumption Theories may facilitate sustainability research, it will also be useful to further this research into the area of innovative solutions.

\subsection{Managerial Implications}

Our study findings indicate that Enthusiasm and Attention is the key dimension of engagement in sustainable consumption, therefore public policy makers and firm managers need to address this dimension when engaging working consumers in sustainable consumption at home and in the workplace environment. Further, research findings suggest that males are less engaged in sustainable consumption than females. To address this resistance from males, companies might develop innovative solutions, such as online advertisements with information about the benefits of use behavior at work for their health and for the environmental preservation. Those ads might pop-up as banners on the computer screens at the end of the day, for example, to remind males to switch off their computer screens and lights in the offices before leaving the premises until next day. Companies might also think of educational strategies which would not hurt their masculine and fearless image by offering training in sustainable consumption behavior in an online environment so that males can do the tasks at their own convenience without others noticing their environment-related educational efforts. Once males will get used to reminders about sustainable consumption behavior at their workplace, they will likely exert such behavior more often in this environment. Another finding suggests that younger people tend to engage in sustainable consumption less often than older consumers. Perhaps introducing an online game with an online voucher for fresh food at coffee shops on site could contribute to encouraging social learning and would foster sustainable consumption behavior of younger consumers. To address fast food consumption in the workplace, companies might introduce short breaks during the work hours and open more cafes in the buildings onsite where different fresh food options would be offered. Also, an onsite shop would also be useful where fresh sandwiches might be sold to employees and such food might be subsidized by the company as a consequence of the savings resulting from sustainable consumption behavior at a workplace.

\subsection{Limitations and Future Research Directions}

As with every empirical study, this study comes with a number of limitations offering directions for future research. First, the study is skewed more towards female consumers. Therefore, future studies should focus on selecting a sample that represents females and males equally. Second, the study is limited to one country under investigation in Western Europe. Therefore, the findings of this study would be approached with caution if applied to other Western countries (e.g., [91]), developing countries or emerging economies (see $[89,92])$. Third, the study did not take into consideration any cultural differences, therefore respondents from other countries might be also included to confirm the generalizability of the study. Finally, this study has only considered one phase of sustainable consumer behavior, that is, use behavior, while future studies might include acquisition or disposal behavior of individuals and test if the same results hold for engagement in sustainable consumption through -acquisition or disposal behavior links in other environments, including at home and in the workplace.

Author Contributions: Conceptualization, L.Š. and J.B.; methodology, J.B., L.Š., A.D., Ž.P. and W.S.; validation, L.Š., J.B. and A.D.; formal analysis, L.Š., J.B. and A.D.; investigation, L.Š., J.B. and A.D.; data curation, L.Š. and A.D.; writing—original draft preparation, L.Š., J.B. and A.D.; writing—review and editing, L.Š., J.B., A.D., Ž.P. and W.S.; visualization, J.B., L.Š. and A.D.; project administration, J.B., L.Š., A.D. and Ž.P.; funding acquisition, L.Š. and J.B. All authors have read and agreed to the published version of the manuscript.

Funding: This research was funded by a grant (No. S-MIP-17-123) from the Research Council of Lithuania. 
Acknowledgments: We would like to thank Andželika Žukauskaite for her contribution to the data collection process. We would like to thank the guest editors and three anonymous reviewers for their detailed comments and manuscript reviews.

Conflicts of Interest: The authors declare no conflict of interest. The funders had no role in the design of the study; in the collection, analyses or interpretation of data; in the writing of the manuscript, or in the decision to publish the results.

\section{Appendix A}

\section{Section A}

\section{Engagement in sustainable consumption measure}

Items adapted from So et al. [34], Calder et al. [59] and Hollebeek et al. [23].

\section{Enthusiasm}

I spend a lot of time thinking how much damage excessive consumption makes to the environment that surrounds us.

I like to feel that with my consumption habits I can contribute to the environmental conservation. I follow sustainable consumption principles passionately.

My life without sustainable consumption principles would not be the same as it is now.

Being able to contribute to environmental sustainability, I feel "a better person".

\section{Attention}

I like to learn more about sustainable consumption practices.

I pay attention to any message about consequences of excessive consumption.

Anything related to sustainable consumption grabs my attention.

I pay a lot of attention to the idea of sustainable consumption.

\section{Identification}

When someone criticizes the idea of sustainable consumption, it feels like a personal insult. I am very interested in what others think about sustainable consumption.

When I talk about sustainable consumption, I usually say "now" rather than "at some point".

Sustainable consumption successes are my successes.

When someone praises activities/habits of sustainable consumption, it feels like a personal compliment.

\section{Absorption}

When I am thinking about sustainable consumption principles/activities, I forget everything else around me.

Time flies when I am thinking how I can contribute to the preservation of the environment.

I find it hard to stop thinking how I can contribute to creating a more sustainable world/preserve the environment.

I feel happy when I can contribute to the promotion of sustainable consumption with my own consumption choices.

\section{Participation/Interaction}

In general, I like to get involved in community discussions on sustainable consumption/ environment preservation.

I am someone who enjoys interacting with like-minded others about sustainable consumption. In general, I thoroughly enjoy interacting with other people about preservation of the environment, exchanging ideas about sustainable consumption and listening to their advice.

I often participate in public activities promoting sustainable consumption/communities. 


\section{Section B}

Sustainable consumption behavior (use phase) at home

Items adapted from Littleford et al. [82], Blok et al. [12], Geng et al. [19], Gupta \& Agrawal [17].

\section{Sustainability principles through saving initiatives}

I follow an idea that sustainable consumption is using things in moderation.

When using things/products, I try to reduce waste.

I take due care to use all things in a proper manner.

I send things for regular service and maintenance.

I switch off my computer when leaving it for a considerable period.

I turn off light when leaving the room to reduce electricity consumption.

I conserve water at home (e.g., showering, making food, cleaning).

\section{Borrowing and sharing things at home}

Whenever possible, I borrow things/means from others.

Whenever possible, I share things/means with others.

I take due care to avoid using one-off dishes and cutlery.

\section{Section C}

\section{Sustainable consumption behavior (use phase) in the workplace}

Items adapted from Littleford et al. [82], Blok et al. [12], Geng et al. [19], Gupta \& Agrawal [17] and Geiger et al. [18].

\section{Sustainability principles through saving initiatives in the workplace}

In the workplace, I follow an idea that sustainable consumption means using things in moderation. When using things/products in the workplace, I try to reduce waste as much as I can.

I prioritize borrowing things/means from others instead of buying them.

I happily share things/means with others.

I take due care to use all things in a proper manner in my workplace.

I take due care to print/copy double sided to save paper.

I switch off my computer when leaving it for a considerable period of time.

I turn off light when leaving the room to reduce electricity consumption.

I conserve water in the workplace.

\section{Avoiding plastic dishes and fast food in the workplace}

I usually eat fast food in the workplace. (R)

I take due care to avoid using one-off dishes and cutlery in the workplace.

\section{Section D}

\section{Demographics}

Please indicate your gender

Please indicate your age

What is your marital status?

Single/have a partner/Married with children/Married without children/other

Please specify your company's profile: International/UK-based/Other 


\section{References}

1. United Nations Sustainable Development Goals. Goal 12-Ensure Sustainable Consumption and Production Patterns. Available online: https://www.un.org/sustainabledevelopment/sustainable-consumption-producti on/ (accessed on 23 April 2020).

2. European Environment Agency. The European Environment-State and Outlook 2020 (SOER 2020). Available online: https://www.eea.europa.eu/soer-2020/at-a-glance (accessed on 14 February 2020).

3. Piwowar-Sulej, K. Pro-environmental Organizational Culture: Its Essence and the Concept of its Operationalization. Sustainability 2020, 12, 4197. [CrossRef]

4. Muster, V.; Schrader, U. Green Work-life Balance: A New Perspective Green HRM. Pers. Ger. J. Res. Hum. Resour. Manag. 2011, 25, 140-156. [CrossRef]

5. Yusoff, Y.M.; Othman, N.Z.; Fernando, Y.; Amran, A.; Surienty, L.; Ramayah, T. Conceptualization of Green Human Resource Management: An Exploratory Study from Malaysian-based Multinational Companies. Int. J. Bus. Manag. Econ. Res. 2015, 6, 158-166.

6. Gadeikienè, A.; Dovalienè, A.; Grase, A.; Banytè, J. Sustainable Consumption Behaviour Spill-over from Workplace to Private Life: Conceptual Framework. Pol. J. Manag. Stud. 2019, 19, 142-154.

7. Piligrimienè, Ž.; Banytė, J.; Virvilaitè, R. Work-life Balance and Sustainable Consumption: Is there a Relation? Transf. Bus. Econ. 2019, 18, 116-127.

8. Killian, S.; Mann, A. When the Damage is Done: Effects of Moral Disengagement on Sustainable Consumption. J. Organ. Psychol. 2020, 20, 120-132.

9. Luchs, M.G.; Phipps, M.; Hill, T. Exploring Consumer Responsibility for Sustainable Consumption. J. Mark. Manag. 2015, 31, 1449-1471. [CrossRef]

10. McGregor, S.L.T. Consumer Perceptions of Responsibility. In Consumer Perception of Prod. Risks Benefits; Emilien, G., Weitkunat, R., Lüdicke, F., Eds.; Springer: Cham, Switzerland, 2017; Volume 23, pp. 567-596.

11. Theodori, G.L.; Luloff, A.E. Position on Environmental Issues and Engagement in Proenvironmental Behaviors. Soc. Nat. Res. 2002, 15, 471-482. [CrossRef]

12. Blok, V.; Wesselink, R.; Studynka, O.; Kemp, R. Encouraging Sustainability in the Workplace: A Survey on the Pro-Environmental Behaviour of University Employees. J. Clean. Prod. 2015, 106, 55-67. [CrossRef]

13. Whitburn, J.; Linklater, W.; Abrahamse, W. Meta-analysis of Human Connection to Nature and Proenvironmental Behavior. Conserv. Biol. 2019, 34, 180-193. [CrossRef]

14. Alcock, I.; White, M.P.; Pahl, S.; Duarte-Davidson, R.; Fleming, L.E. Associations Between Pro-Environmental Behaviour and Neighbourhood Nature, Nature Visit Frequency and Nature Appreciation: Evidence from a Nationally Representative Survey in England. Environ. Int. 2020, 136, 105441. [CrossRef] [PubMed]

15. Kadic-Maglajlic, S.; Arslanagic-Kalajdzik, M.; Micevski, M.; Dlacic, J.; Zabkar, V. Being Engaged is a Good Thing: Understanding Sustainable Consumption Behaviour among Young Adults. J. Bus. Res. 2019, 104, 644-654. [CrossRef]

16. Hosta, M.; Zabkar, V. Antecedents of Environmentally and Socially Responsible Sustainable Consumer Behaviour. J. Bus. Ethics 2020. [CrossRef]

17. Gupta, S.; Agrawal, R. Environmentally Responsible Consumption: Construct Definition, Scale Development, and Validation. Corp. Soc. Responsib. Environ. Manag. 2018, 25, 523-536. [CrossRef]

18. Geiger, S.M.; Fischer, D.; Schrader, U. Measuring What Matters in Sustainable Consumption: An Integrative Framework for The Selection of Relevant Behaviors. Sustain. Dev. 2018, 26, 18-33. [CrossRef]

19. Geng, D.; Liu, J.; Zhu, Q. Motivating Sustainable Consumption among Chinese Adolescents: An Empirical Examination. J. Clean. Prod. 2017, 141, 315-322. [CrossRef]

20. Joshi, Y.; Rahman, Z. Determinants of Sustainable Consumption Behaviour: Review and Conceptual Framework. In Green Initiatives for Business Sustainability and Value Creation; Paul, A.K., Bhattacharyya, D.K., Anand, S., Eds.; IGI Global: Hershey, PA, USA, 2017; pp. 239-262.

21. Wesselink, R.; Blok, V.; Ringersma, J. Pro-environmental Behaviour in the Workplace and the Role of Managers and Organization. J. Clean. Prod. 2017, 168, 1679-1687. [CrossRef]

22. Babikova, K.; Bucek, J. A Model Replication with an Extension of Students' Perception of Prospective Employer Attractiveness. J. Competit. 2019, 11, 5-21. [CrossRef]

23. Hollebeek, L.D.; Glynn, M.S.; Brodie, R.J. Consumer Brand Engagement in Social Media: Conceptualization, Scale Development and Validation. J. Interact. Mark. 2014, 28, 149-165. [CrossRef] 
24. Hollebeek, L.D.; Conduit, J.; Sweeney, J.; Soutar, G.; Karpen, I.O.; Jarvis, W.; Chen, T. Epilogue to the Special Issue and Reflections on the Future of Engagement Research. J. Mark. Manag. 2016, 32, 586-594. [CrossRef]

25. Thakur, R. Understanding Customer Engagement and Loyalty: A Case of Mobile Devices for Shopping. J. Ret. Cons. Serv. 2016, 32, 151-163. [CrossRef]

26. Piligrimiene, Z.; Zukauskaite, A.; Korzilius, H.; Banyte, J.; Dovaliene, A. Internal and External Determinants of Consumer Engagement into Sustainable Consumption. Sustainability 2020, 12, 1349. [CrossRef]

27. Saks, A.M. Antecedents and Consequences of Employee Engagement. J. Manag. Psych. 2006, 21, 600-619. [CrossRef]

28. Salanova, M.; Schaufeli, W.B. A Cross-National Study of Work Engagement as a Mediator between Job Resources and Proactive Behaviour. Int. J. Hum. Res. Manag. 2008, 19, 116-131. [CrossRef]

29. Motyka, B. Employee Engagement and Performance: A Systematic Literature Review. Int. J. Manag. Econ. 2018, 54, 227-244. [CrossRef]

30. Gangale, F.; Mengolini, A.; Onyeji, I. Consumer Engagement: An Insight from Smart Grid Projects En Europe. Energy Policy 2013, 60, 621-628. [CrossRef]

31. Miao, L.; Wei, W. Consumers' Pro-environmental Behavior and its Determinants in the Lodging Segment. J. Hosp. Tour. Res. 2016, 40, 319-338. [CrossRef]

32. Salciuviene, L. Consequences of Engagement into Sustainable Consumption in the Workplace: The Role of Moral Climate. In Proceedings of the 19th ERSCP —Circular Europe for Sustainability: Design, Production and consumption conference, Barcelona, Spain, 15-18 October 2019.

33. Salciuviene, L.; Buenaventura, V.E.C.; Lee, K. Employee Proactiveness to Engage in Sustainable Consumption Leading to Societal Benefits. Eng. Econ. 2019, 30, 112-120. [CrossRef]

34. So, K.K.F.; King, C.; Sparks, B. Customer Engagement with Tourism Brands: Scale Development and Validation. J. Hosp. Tour. Res. 2014, 38, 304-329. [CrossRef]

35. Hand, C. Biology and Being Green: The Effect of Prenatal Testosterone Exposure on Pro-environmental Consumption Behaviour. J. Bus. Res. 2019. [CrossRef]

36. Hunter, L.; Hatch, A.J. Cross-National Gender Variation in Environmental Behaviours. Soc. Sci. Q. 2004, 85, 677-694. [CrossRef]

37. Vivek, S.D.; Beatty, S.E.; Dalela, V.; Morgan, R.M. A Generalized Multidimensional Scale for Measuring Customer Engagement. J. Mark. Theor. Pract. 2014, 22, 401-420. [CrossRef]

38. Pepper, M.; Jackson, T.; Uzzell, D. An Examination of the Values that Motivate Socially Conscious and Frugal Consumer Behaviours. Int. J. Cons. Stud. 2009, 33, 126-136. [CrossRef]

39. Liobikienè, G.; Poškus, M.S. The Importance of Environmental Knowledge for Private and Public Sphere Pro-environmental Behavior: Modifying the Value-Belief-Norm Theory. Sustainability 2019, 11, 3324. [CrossRef]

40. Park, J.; Ha, S. Understanding Pro-environmental Behavior: A Comparison of Sustainable Consumers and Apathetic Consumers. Int. J. Retail. Distrib. Manag. 2012, 40, 388-403. [CrossRef]

41. Wang, P.; Liu, Q.; Qi, Y. Factors Influencing Sustainable Consumption Behaviors: A Survey of the Rural Residents in China. J. Clean. Prod. 2014, 63, 152-165. [CrossRef]

42. Wu, C.; Zhou, X.; Song, M. Sustainable Consumer Behavior in China: An Empirical Analysis from the Midwest Regions. J. Clean. Prod. 2016, 134, 147-165. [CrossRef]

43. Dong, X.; Li, H.; Liu, S.; Cai, C.; Fan, X. How does Material Possession Love Influence Sustainable Consumption Behavior towards the Durable Products? J. Clean. Prod. 2018, 198, 389-400. [CrossRef]

44. Wagner, M. Environmental management activities and sustainable HRM in German Manufacturing Firms-Incidence, Determinants, and Outcomes. Pers. Ger. J. Res. Hum. Resour. Manag. 2011, 25, 157-177. [CrossRef]

45. Zibarras, L.; Judson, H.; Barnes, C. Promoting Environmental Behaviour in the Workplace: A Survey of UK Organisations. pp. 1-15. Available online: https://greenedge.co.za/files/Downloads-Pro-environmental-beh aviour-in-the-workplace-UK-survey-2012.pdf (accessed on 3 August 2020).

46. Yuriev, A.; Boiral, O.; Francoeur, V.; Paillé, P. Overcoming the Barriers to Pro-environmental Behaviors in the Workplace: A Systematic Review. J. Clean. Prod. 2018, 182, 379-394. [CrossRef]

47. Paille, P.; Amara, N.; Halilem, N. Greening the Workplace through Social Sustainability among Co-workers. J. Bus. Res. 2018, 89, 305-312. [CrossRef] 
48. Brodie, R.J.; Hollebeek, L.D.; Jurić, B.; Ilić, A. Customer Engagement: Conceptual Domain, Fundamental Propositions, and Implications for Research. J. Serv. Res. 2011, 14, 252-271. [CrossRef]

49. Ellabban, O.; Abu-Rub, H. Smart Grid Customers' Acceptance and Engagement: An Overview. Renew. Sustain. Energy Rev. 2016, 65, 1285-1298. [CrossRef]

50. Bly, S.; Gwozdz, W.; Reisch, L.A. Exit from the High Street: An Exploratory Study of Sustainable Fashion Consumption Pioneers. Int. J. Cons. Stud. 2015, 39, 125-135. [CrossRef]

51. Armstrong, C.M.J.; Connell, K.Y.H.; Lang, C.; Ruppert-Stroescu, M.; LeHew, M.L. Educating for Sustainable Fashion: Using Clothing Acquisition Abstinence to Explore Sustainable Consumption and Life beyond Growth. J. Cons. Pol. 2016, 39, 417-439. [CrossRef]

52. Connell, K.Y.H.; Kozar, J.M. Environmentally Sustainable Clothing Consumption: Knowledge, Attitudes, and Behavior. In Roadmap to Sustainable Textiles and Clothing; Muthu, S.S., Ed.; Springer: Singapore, 2014; pp. 41-61.

53. Jones, P.; Hillier, D.; Comfort, D. Shopping for Tomorrow: Promoting Sustainable Consumption within Food Stores. Br. Food J. 2011, 113, 935-948. [CrossRef]

54. Marzouk, O.A.; Mahrous, A.A. Sustainable Consumption Behavior of Energy and Water-efficient Products in a Resource-constrained Environment. J. Glob. Mark. 2020, in press. [CrossRef]

55. Rist, T.; Masoodian, M. Promoting Sustainable Energy Consumption Behavior through Interactive Data Visualizations. Multimodal Technol. Interact. 2019, 3, 56. [CrossRef]

56. Ntanos, S.; Kyriakopoulos, G.; Skordoulis, M.; Chalikias, M.; Arabatzis, G. An Application of the New Environmental Paradigm (NEP) Scale in a Greek Context. Energies 2019, 12, 239. [CrossRef]

57. Jackson, T. Motivating Sustainable Consumption. Sustain. Dev. Res. Net. 2005, 29, 30-40.

58. Muster, V. Companies Promoting Sustainable Consumption of Employees. J. Cons. Pol. 2011, 34, 161-174. [CrossRef]

59. Calder, B.J.; Malthouse, E.C.; Schaedel, U. An Experimental Study of the Relationship between Online Engagement and Advertising Effectiveness. J. Interact. Mark. 2009, 23, 321-331. [CrossRef]

60. Mischel, W.; Shoda, Y. A Cognitive-Affective System Theory of Personality: Reconceptualizing Situations, Dispositions, Dynamics, and Invariance in Personality Structure. Psychol. Rev. 1995, 102, 246-268. [CrossRef] [PubMed]

61. McLeod, S. Bandura-Social Learning Theory. Available online: https://www.simplypsychology.org/bandu ra.html (accessed on 3 August 2020).

62. Bandura, A. Social Learning Theory; Prentice Hall: Englewood Cliffs, NJ, USA, 1977.

63. Benson, N. What is Collaborative Consumption? Platforms and Participation of People in Collaborative Consumption-Impact of the New Technologies. Int. J. Innov. Manag. Technol. 2018, 9, 240-245.

64. Dowling, J.; Pfeffer, J. Organizational Legitimacy: Social Values and Organizational Behavior. Pac. Sociol. Rev. 1975, 18, 122-136. [CrossRef]

65. Miller, D.; Karakowsky, L. Gender Influences as an Impediment to Knowledge Sharing: When Men and Women Fail to Seek Peer Feedback. J. Psychol. 2005, 139, 101-118. [CrossRef] [PubMed]

66. Jain, S.K.; Kaur, G. Role of Socio-demographics in Segmenting and Profiling Green Consumers. J. Int. Cons. Mark. 2006, 18, 107-146. [CrossRef]

67. Roberts, J.; Lilien, G. Explanatory and Predictive Models of Consumer Behaviour. Handb. Oper. Res. Manag. Sci. 1993, 5, 27-82.

68. Schultz, P.W. Inclusion with Nature: The Psychology of Human-Nature Relations. In Psychology of Sustainable Development; Schmuck, P., Schultz, W.P., Eds.; Springer: Boston, MA, USA, 2002; pp. 61-78.

69. Mostafa, M. Gender Differences in Egyptian Consumers' Green Purchase Behaviour: The Effects of Environmental Knowledge, Concern and Attitude. Int. J. Cons. Stud. 2007, 31, 220-229. [CrossRef]

70. Lee, K.M. Nation Branding and Sustainable Competitiveness of Nations. Ph.D. Thesis, University of Twente, Enschede, The Netherlands, 2009.

71. Sundie, J.M.; Kenrick, D.T.; Griskevicius, V.; Tybur, J.M.; Vohs, K.D.; Beal, D.J. Peacocks, Porsches, and Thorstein Veblen: Conspicuous Consumption as a Sexual Signaling system. J. Pers. Soc. Psychol. 2011, 100, 664-680. [CrossRef]

72. Polk, M. Are Women Potentially More Accommodating than Men to a Sustainable Transportation System in Sweden? Transp. Res. D Transp. Environ. 2003, 8, 75-95. [CrossRef] 
73. Schwartz, S.H.; Rubel, T. Sex Differences in Value Priorities: Cross-cultural and Multi-method Studies. J. Pers. Soc. Psychol. 2005, 89, 1010-1028. [CrossRef]

74. Laroche, M.; Bergeron, J.; Barbaro-Forleo, G. Targeting Consumers who are Willing to Pay More for Environment Friendly Products. J. Cons. Mark. 2001, 18, 503-520. [CrossRef]

75. Shim, S.; Warrington, P.; Goldberry, E.A. Personal Value-Based Model of College Students' Attitudes and Expected Choice Behavior Regarding Retailing Careers. Fam. Cons. Sci. 1999, 28, 28-51. [CrossRef]

76. Remenova, K.; Jankelova, N. How Successfully can Decision-Making Style Predict the Orientation toward Well- or Ill-Structured Decision-Making Problems. J. Compet. 2019, 11, 99-115. [CrossRef]

77. Pinto, D.C.; Herter, M.M.; Rossi, P.; Borges, A. Going Green for Self or the Others? Gender and Identity Salience Effects on Sustainable Consumption. Int. J. Cons. Stud. 2014, 38, 540-549. [CrossRef]

78. James, J.B.; Wink, P. The Crown of Life: Dynamics of the Early Postretirement Period; Springer: New York, NY, USA, 2007.

79. Weiss, R.S.; Bass, S.A. Challenges of the Third Age: Meaning and Purpose in Later Life; Oxford University Press: Oxford, UK, 2002.

80. Moen, P.; Flood, S. Limited Engagements? Women's and Men's Work/Volunteer Time in the Encore Life Course Stages. Soc. Probl. 2013, 60, 206-233.

81. Kreuzer, C.; Weber, S.; Off, M.; Hackenberg, T.; Birk, C. Shedding Light on Realized Sustainable Consumption Behavior and Perceived Barriers of Young Adults for Creating Stimulating Teaching-learning Situations. Sustainability 2019, 11, 2587. [CrossRef]

82. Burke, M.; Conn, W.D.; Lutz, R.J. Using Psychographic Variables to Investigate Product Disposition Behaviour. In Research frontiers in marketing: Dialogues and directions, Proceedings of the Educators Conference, Chicago, IL, USA, 6-9 August 1978; Series No. 43; Subhash, C.J., Ed.; American Marketing Association: Chicago, IL, USA, 1978; pp. 321-326.

83. Littleford, C.; Ryley, T.J.; Firth, S.K. Context, Control and the Spillover of Energy Use Behaviours between Office and Home Settings. J. Environ. Psychol. 2014, 40, 157-166. [CrossRef]

84. Ng, E.S.; Burke, R.J. Predictor of Business Students' Attitudes toward Sustainable Business Practices. J. Bus. Ethics 2010, 95, 603-615. [CrossRef]

85. Griskevicius, V.; Cantú, S.M.; van Vugt, M. The evolutionary Bases for Sustainable Behavior: Implications for Marketing, Policy, and Social Entrepreneurship. J. Public Policy Mark. 2012, 31, 115-128. [CrossRef]

86. Dholakia, R.R. Going Shopping: Key Determinants of Shopping Behaviours and Motivation. Int. J. Retail. Distrib. Manag. 1999, 27, 154-165. [CrossRef]

87. Kending, S.M.; Bianchi, S.M. Single, Cohabiting, and Married Mothers' Time with Children. J. Marriage Fam. 2008, 70, 1228-1240. [CrossRef]

88. Wight, D.; Parkes, A.; Strange, V.; Allen, E.; Bonell, C.; Henderson, M. The Quality of Young People's Heterosexual Relationships: A Longitudinal Analysis of Characteristics Shaping Subjective Experience. Perspect. Sex. Reprod. Health. 2008, 40, 226-237. [CrossRef] [PubMed]

89. Gandhi, M.; Kaushik, N. Socially Responsible Consumption Behaviour-An Indian Perspective. Soc. Responsib. J. 2016, 12, 85-102. [CrossRef]

90. Kirchler, E.; Rodler, C.; Hölzl, E.; Meier, K. Conflict and Decision-Making in Close Relationships: Love, Money and Daily Routines; Psychology Press: Hove, UK, 2001.

91. Fischer, D.; Böhme, T.; Geiger, S.M. Measuring Young Consumers' Sustainable Consumption Behavior: Development and Validation of the YCSCB Scale. Young Cons. 2017, 18, 312-326. [CrossRef]

92. Ukenna, S.I.; Nkamnebe, A.D. Sustainable Consumption Behavior in Sub-Saharan Africa: A conceptual framework. Thund. Int. Bus. Rev. 2017, 59, 33-50. [CrossRef]

(C) 2020 by the authors. Licensee MDPI, Basel, Switzerland. This article is an open access article distributed under the terms and conditions of the Creative Commons Attribution (CC BY) license (http://creativecommons.org/licenses/by/4.0/). 